\title{
PACAP type I receptor activation regulates ECL cells and gastric acid secretion
}

\author{
Ningxin Zeng, Christoph Athmann, Tao Kang, Rong-Ming Lyu, John H. Walsh, \\ Gordon V. Ohning, George Sachs, and Joseph R. Pisegna
}

\begin{abstract}
The Center for Ulcer Research and Education: Veterans Administration/University of California-Los Angeles Digestive Diseases Research Center, Veterans Affairs Greater Los Angeles Heath Care System at West Los Angeles; and Departments of Physiology and Medicine, University of California-Los Angeles; Los Angeles, California 90073, USA

Address correspondence to: George Sachs, Veterans Affairs Greater Los Angeles Heath Care System at West Los Angeles, Building 113, Room 326, Los Angeles, California 90073, USA. Phone: (310) 268-3923; Fax: (310) 312-9478; E-mail: gsachs@ucla.edu. Or to: Joseph R. Pisegna, Veterans Affairs Greater Los Angeles Heath Care System at West Los Angeles, Building 115, Room 316, Los Angeles, California 90073, USA. Phone: (310) 478-3711 ext. 41940; Fax: (310) 268-4963; E-mail: JPisegna@ucla.edu.
\end{abstract}

Received for publication June 9, 1999, and accepted in revised form September 17, 1999.

\begin{abstract}
Pituitary adenylate cyclase activating polypeptide (PACAP) is present in gastric nerves, and PACAP receptors (PAC1) are found on gastric enterochromaffin-like (ECL) cells. Expression of PAC1 splice variants in purified ECL cells was determined by RT-PCR. PACAP effects on ECL cells were analyzed by video imaging of $\left[\mathrm{Ca}^{2+}\right]_{\mathrm{i}}$ and histamine release; its effects on gastric glands were examined by confocal microscopy of $\left[\mathrm{Ca}^{2+}\right]_{i}$ in ECL and parietal cells. PACAP action on D cells was measured by $\left[\mathrm{Ca}^{2+}\right]_{\mathrm{i}}$ and radioimmunoassay. PACAP effects on acid secretion were determined in fistula rats with or without neutralizing anti-somatostatin antibodies. All splice variants of PAC1 were found, but vasoactive intestinal polypeptide (VIP) receptor (VPAC) products were absent. PACAP-27 and -38 dose-dependently raise $\left[\mathrm{Ca}^{2+}\right]_{\mathrm{i}}$ in ECL cells and stimulate histamine release. VIP had a much lower affinity, which demonstrates the presence of PAC1 but not VPAC. PACAP elevated $\left[\mathrm{Ca}^{2+}\right]_{i}$ in ECL and parietal cells of superfused gastric glands, but only the parietal cell signal was inhibited by ranitidine, showing the absence of PAC1 on parietal cells and demonstrating functional coupling between the cell types. PACAP and VIP stimulated calcium signaling and somatostatin release from $D$ cells with almost equal efficacy. Acid secretion was stimulated after intravenous injection of PACAP into rats treated with somatostatin antibody. PACAP is a candidate as a mediator of neural regulation of acid secretion.
\end{abstract}

J. Clin. Invest. 104:1383-1391 (1999).

\section{Introduction}

The regulation of acid secretion has been divided into cephalic and peripheral (gastric and intestinal) phases (1). The cephalic phase of gastric acid secretion originates in the central nervous system and impacts the hypothalamus; signals travel via the vagus nerve to the myenteric plexuses of the gastric mucosa. In the succeeding neural network, a variety of secondary neurons signal the gastric fundic and antral epithelia to influence gastric acid secretion by either primary or secondary action, namely, direct effects on parietal cells or gastric epithelial endocrine cells. The peripheral phase of acid secretion regulation involves local signaling within a variety of endocrine cells, transmitting regulatory information to the secretory cells of the gastric mucosa; the peripheral phase is more limited than the cephalic phase in terms of the possible mediators involved (2). Studies of isolated gastric endocrine cells have proved useful in defining the interactions of various signals in the regulation of gastric acid secretion, but such studies must be placed in context when considering their physiological implications. The isolated rabbit gastric gland is a more integrated model than that provided by isolated cells.

With the isolation and purification (to between $85 \%$ and $95 \%$ ) of functional enterochromaffin-like (ECL) cells from the rat gastric mucosa, a variety of receptors has been defined on this cell type. This has been done by measurement of calcium signals under superfusion conditions using video microscopy, and by histamine or pancreostatin release by radioimmunoassay under static conditions (3-5). When histamine release is measured in a static system, cross-talk is a problem. Superfusion of isolated, enriched ECL cells while measuring responses of intracellular calcium $\left[\mathrm{Ca}^{2+}\right]_{\mathrm{i}}$ eliminates cross-talk between possible contaminating gastric endocrine cells. Nevertheless, few (if any) inconsistencies have been found between the results of video-imaging and release measurements in this particular preparation. In this preparation, there are less than $2 \% \mathrm{D}$ cells, and the addition of somatostatin antibody has not affected either calcium signaling or histamine release in response to a variety of agonists $(3,4)$.

Histamine, released from ECL cells, is the most important direct stimulant of acid secretion, as shown by the broad efficacy of histamine-2 receptor antagonists as full inhibitors of gastrin and partial inhibitors of vagally stimulated acid secretion (6). The involvement of ECL cells in mediation of the cephalic (neural) phase of gastric acid secretion has been less clear. The atropine sensitivity of cephalic stimulation of acid secretion pointed 
to a major role for muscarinic receptors in this pathway. The parietal cell possesses $\mathrm{M}_{3}$ muscarinic receptors, and yet $\mathrm{M}_{1}$-selective antagonists were the most effective in suppressing acid secretion (7). Only a few isolated, purified ECL cells have responded to carbachol with changes of $\left[\mathrm{Ca}^{2+}\right]_{\mathrm{i}}$. Carbachol stimulation of histamine release has not been observed. The ECL cell, if it plays a role in the neural pathway after the cephalic phase of secretion, is not responsive to the release of acetylcholine from cholinergic nerve fibers $(4,5)$. On the other hand, about $60 \%$ of centrally stimulated acid secretion in the rat is blocked by histamine- 2 antagonism (6), suggesting that a neural mediator of ECL cell function must be present to explain this effect of histamine-2 antagonists.

Pituitary adenylate cyclase-activating polypeptides (PACAP-27 and PACAP-38), the most recently described members of the family of peptide hormones that includes secretin, vasoactive intestinal polypeptide (VIP), and glucagon (8), are present in the enteric nervous system and in gastric nerve fibers (9). The PACAP type I receptor (PAC1) has been cloned, and 4 splice variants have been described, coupled to both cAMP and phospholipase C, with similar potencies (10-15). PAC1 belongs to a family of receptors that includes the VIP receptors VPAC1 and VPAC2, as well as secretin and glucagon receptors. Although VIP and PACAP have almost the same potency at VPAC, VIP is 1,000-fold less potent than PAC1, enabling functional distinction between PAC and the VPAC group of receptors $(14,15)$. The presence of the PAC1 splice variants, their coupling mechanisms for activation of ECL cell histamine release, and their consequent effects on parietal cell function have not been described previously.

Central injection of PACAP stimulates acid secretion (16). Preliminary reports have shown that not only is PACAP a potent and effective stimulant of histamine release from ECL cells $(5,17)$, but that it also results in both transient and steady-state elevations of $\left[\mathrm{Ca}^{2+}\right]_{i}(17)$. Peripheral injection has been variously reported to either have no effect or to inhibit gastrin-stimulated acid secretion. This makes its candidacy as a mediator of stimulation of gastric acid secretion questionable $(18,19)$. Like gastrin, PACAP stimulates growth of ECL cells in vitro (20). We are therefore faced with the paradox of an effective in vitro stimulant of gastric ECL cell function acting as an inhibitor of acid secretion in vivo $(18,19)$.

The studies discussed here show that PACAP is an effective ligand on PAC1 of isolated ECL cells (and of ECL cells in gastric glands) in terms of calcium signaling and histamine release. The histamine released in glands stimulates calcium signaling in parietal cells, demonstrating coupling of ECL and parietal cells in an in vitro model. PACAP can also stimulate somatostatin release from isolated D cells by interaction with VPAC. To reconcile these in vitro data with previous reports showing lack of acid secretion stimulation, acid secretion was monitored in fistula rats in the absence or presence of a neutralizing anti-somatostatin antibody. Stimulation of acid secretion was observed in these experiments; hence PACAP is apparently able to stimulate ECL cells, as well as D cells, in vivo. With cholinergic stimulation, there is also inhibition of D-cell function (4). The outcome of neural release of PACAP is probably determined by a balance between activation and inhibition of the regulatory pathways of acid secretion, depending on when and where PACAP and acetylcholine are released from gastric nerves.

\section{Methods}

Isolation and purification of ECL cells. Rat gastric ECL cells were isolated by a combination of elutriation and density gradient centrifugation as described previously. Briefly, approximately 5 rat stomachs were digested to yield approximately $10^{6}$ cells after elutriation and density gradient centrifugation $(3,4)$. Cell viability was determined using trypan blue exclusion. Cellular purity for each experiment was determined by immunostaining with anti-histidine decarboxylase antibody and anti-histamine antibody, and by using the fluorescent dye acridine orange, which accumulates in histamine-containing vacuoles. With use of these techniques, the freshly isolated cell population consisted of approximately $65 \%$ ECL cells. These isolated ECL cells were rinsed by gentle centrifugation in growth medium containing DMEM/F12 supplemented with $2 \mathrm{mg} / \mathrm{mL}$ BSA, $2.5 \%$ FCS, $100 \mu \mathrm{M}$ hydrocortisone, $1 \%$ penicillin, $1 \%$ streptomycin, $5 \mathrm{mg} / \mathrm{mL}$ insulin, $5 \mathrm{mg} / \mathrm{mL}$ transferrin, and $5 \mu \mathrm{g} / \mathrm{L}$ sodium selenite. Enrichment of the primary culture was performed by plating the cell suspension onto glass coverslips precoated with Cell-Tak (Collaborative Research, Belmont, California, USA)and incubating at $37^{\circ} \mathrm{C}$ for 48 hours. Incubation at $37^{\circ} \mathrm{C}$ for 45 minutes resulted in almost all of the ECL cells adhering to the coverslip. Then $1 \mathrm{~mL}$ of growth medium was added to each well, and the ECL cells were cultured for 48 hours. The ECL cell population was always enriched to over $85 \%$, and sometimes was as high as $95 \%$. All experiments reported here on ECL cells (i.e., calcium imaging, histamine release, and the cells as a source of membranes or RNA) were carried out after short-term cell culture. D cells constituted less than $2 \%$ of the population, and in many experiments, neutralizing anti-somatostatin antibody had no effect either on calcium signaling or on histamine release.

Parietal cells were obtained at $85 \%$ purity from the elutriation used for the ECL cell preparation in a large cell fraction.

RT-PCR analysis and cDNA synthesis. RNA was extracted from approximately 1 gram of a purified ECL cell preparation using the FastTrack RNA purification kit from Invitrogen Corp. (La Jolla, California, USA). Total RNA $(5 \mu \mathrm{g})$ from enriched rat ECL cells was used to synthesize cDNA by reverse transcription with oligo-dT primers (Boehringer-Mannheim). PCR was performed in low-salt Taq DNA polymerase buffer and 5 units of Taq DNA polymerase (Stratagene, La Jolla, California, USA) in the presence of oligonucleotide primers as follows: an initial step of one cycle at $94^{\circ} \mathrm{C}$ for 2 minutes, $57^{\circ} \mathrm{C}$ for 1 minute, and $72^{\circ} \mathrm{C}$ for 2 minutes; 30 cycles of $94^{\circ} \mathrm{C}$ for 1 minute, $57^{\circ} \mathrm{C}$ for 1 minute, and $72^{\circ} \mathrm{C}$ for 2 minutes; and a final extension step of one cycle at $94^{\circ} \mathrm{C}$ for 1 minute, $57^{\circ} \mathrm{C}$ for 1 minute, and $72^{\circ} \mathrm{C}$ for 15 minutes. To standardize the amount and quality of total RNA used for RT-PCR, the same samples were analyzed for histidine decarboxylase, $\mathrm{H}, \mathrm{K}$-ATPase, and $\beta$-actin as controls. Whereas histidine decarboxylase is expressed in ECL cells and H,K-ATPase 
Table 1

Primer sequences

\begin{tabular}{|c|c|c|c|}
\hline & Upper primer & Lower primer & Size \\
\hline \multirow[t]{2}{*}{ PAC1 } & $\begin{array}{l}5^{\prime}-\mathrm{CGAGTGGACAGTGGCAGGCGGTGA}-3^{\prime} \\
(52-77)\end{array}$ & $\begin{array}{l}5^{\prime} \text {-CAGTAGTGAGGGTGGCGAGGGAAGT-3' } \\
(611-636)\end{array}$ & $584 \mathrm{bp}$ \\
\hline & $\begin{array}{l}5^{\prime} \text {-GCTCTCCCTGACTGCTCTCCTGCTG-3' } \\
(145-170)\end{array}$ & $\begin{array}{l}5^{\prime} \text {-CAGTAGGTGTCCCCCAGCCGATGAT-3' } \\
(935-960)\end{array}$ & $815 \mathrm{bp}$ \\
\hline HDC & $\begin{array}{l}5^{\prime} \text {-GCTCGTCTTGTTGCCTATGCCTCTG } \\
(631-656)\end{array}$ & $\begin{array}{l}5^{\prime}-\text { TCACCCCGAAGGACCGAATCACAAA } \\
(1174-1199)\end{array}$ & $568 \mathrm{bp}$ \\
\hline H,K-ATPase & $\begin{array}{l}5^{\prime}-\text { ATCATTGGACGCATCGCCTCTCTGG } \\
(1029-1054)\end{array}$ & $\begin{array}{l}5^{\prime} \text {-GTCTTCTGTGGTGTCCGCCGTGTGG } \\
(1424-1449)\end{array}$ & $420 \mathrm{bp}$ \\
\hline$\beta$-actin & $\begin{array}{l}5^{\prime}-\text { TTGTAACCAACTGGGACGATATGG } \\
(538-562)\end{array}$ & $\begin{array}{l}5^{\prime} \text {-GATCTTGATCTTCATGGTGCTAGG } \\
(1302-1326)\end{array}$ & $764 \mathrm{bp}$ \\
\hline
\end{tabular}

HDC, histidine decarboxylase.

in parietal cells, $\beta$-actin is expressed in all cell types of the mucosa. The sense and antisense primers used are summarized in Table 1. Amplified products were purified from $0.7 \%$ agarose gels using the Quiaex Gel Extraction Kit (QIAGEN Inc., Valencia, California, USA) and subcloned into pPCR-Script Amp SK(+) (Stratagene). DNA sequence analysis was performed on $500 \mathrm{fmol}$ of extracted DNA product using a DNA Autoanalyzer.

Measurement of $\mathrm{Ca}^{2+}{ }_{i}$ using video microscopy. D cells or ECL cells were loaded with $2 \mu \mathrm{M}$ Fura-2/AM for 30 minutes at $37^{\circ} \mathrm{C}$, washed with growth medium, and placed in a heated chamber (Medical Systems Corp., Greenvale, New York, USA). Temperature was maintained at a constant $37^{\circ} \mathrm{C}$. The chamber was perfused with Ringer's solution, with or without the indicated peptides, at a rate of 5 $\mathrm{mL} / \mathrm{min}$; the effluent was constantly removed with a peristaltic pump. Approximately 20 cells per field were imaged; Fura-2 fluorescence was measured using a Nikon Fluo $\times 40$ objective (Nikon, Inc., New York, New York, USA) with a Zeiss Axiovert S100 TV microscope (Carl Zeiss Inc., Thornwood, New York, USA) connected to a computer that was programmed to rapidly alternate between the excitation wavelengths of $340 \mathrm{~nm}$ and 380 $\mathrm{nm}$. Image pairs were captured under the control of Image-1/FL software (Universal Imaging Corp., West Chester, Pennsylvania, USA); resulting data was expressed as the ratio of fluorescence at the 2 wavelengths. Maximal and minimal fluorescence was achieved by adding $10 \mu \mathrm{M}$ ionomycin followed by $20 \mathrm{mM}$ EGTA. Calculation of $\left[\mathrm{Ca}^{2+}\right]_{\mathrm{i}}$ was performed using previously described formulas with slight modifications (3). The data in the figures represent the averages of at least 4 experiments.

Confocal microscopy of rabbit gastric glands. Rabbit fundic gastric glands were prepared by previously published methods. Briefly, under anesthesia, high-pressure aortic perfusion with mammalian Ringer's solution was used to separate the epithelial layer from the submucosa. The epithelium was stripped off and minced with scissors, and then digested with collagenase, as described previously. The glands were washed by allowing them to settle, and were kept at room temperature until use. This is a well-characterized preparation, which responds to histamine, gastrin, and carbachol in terms of stimulation of acid secretion and changes of intracellular messengers in the parietal cells (21). (A preparation of rat gastric glands has not been characterized, so rabbit glands were chosen as an integrated model in which to investigate the action of PACAP on ECL cells in situ and on parietal cells.) The preparation has been shown to respond physiologically to ligands such as gastrin with changes similar to those found in rats and humans. It is also a basal secretor similar to the human stomach. It is to be expected that the ECL cell of the rabbit has a generally similar response to that of the rat; this expectation is borne out by the experimental results discussed below.

The glands were loaded with $5 \mu \mathrm{M}$ Fluo-4/AM for 30 minutes and then placed on a coverslip coated with CellTak in a superfusion chamber at $37^{\circ} \mathrm{C}$. The Cell-Tak kept the glands on the coverslip for the duration of the assay. Dye fluorescence was measured at $525 \mathrm{~nm}$ with excitation at $488 \mathrm{~nm}$. The ligands (100 nM PACAP, 10

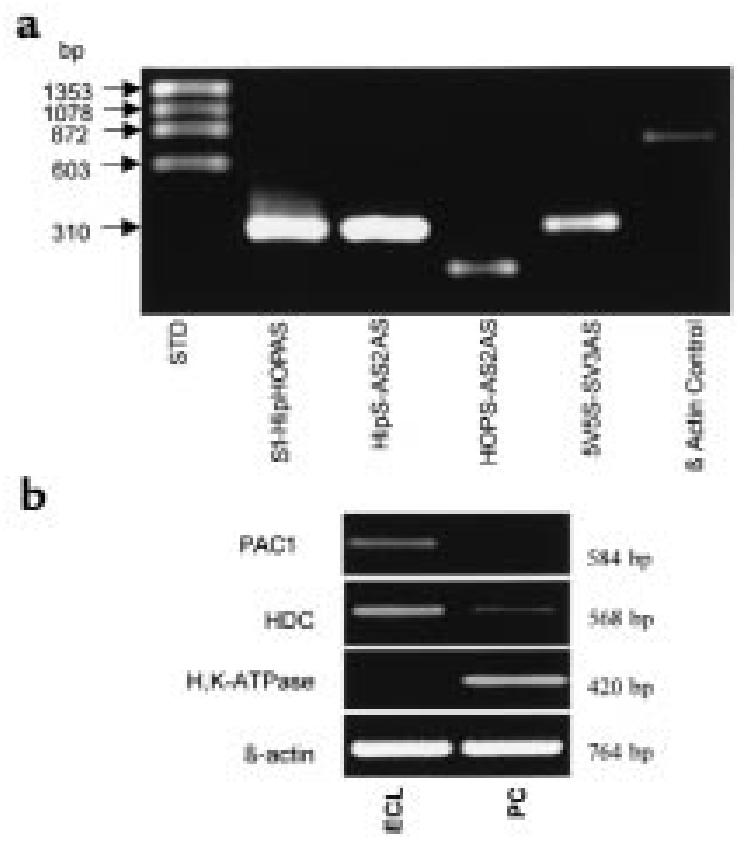

Figure 1

RT-PCR of ECL-cell and parietal-cell RNA. (a) RT-PCR performed on ECL cell RNA using primers specific to the third intracellular loop splice variants. Sense primers (S1, HipS, HOPS, SV3AS) were used together with antisense primers (S1, HipS, HOPS, SV3AS) that spanned the intron-exon junctions as described previously (23). Amplification using primers for $\beta$-actin was performed as a control and is shown in the last lane. (b) RT-PCR performed on purified ECL and parietal cells (PC). The primers used were designed to amplify PAC1, histidine decarboxylase (HDC), H,K-ATPase, and $\beta$-actin in these 2 purified cell preparations $(>85 \%)$. 
$\mu \mathrm{M}$ histamine, or $100 \mu \mathrm{M}$ ranitidine) were added during the perfusion with Ringer's solution. The relative changes in $\left[\mathrm{Ca}^{2+}\right]_{\mathrm{i}}$ were monitored on a selected region during the experiment, showing individual gastric glands at $\times 63$, scanning $512 \times 512$ pixels every other second. The region of interest was highlighted on the image; the numbers on Figure 1a indicate the position of each image on the scan.

Histamine release. Histamine release was determined after 48 hours of culture by incubating ECL cells on coverslips precoated with Cell-Tak in 6-well plates containing growth medium. Growth medium was replaced 3 hours before the experiments. The cultured ECL cells were rinsed with Ringer's solution and incubated in test medium for 60 minutes at $37^{\circ} \mathrm{C}$. Approximately 20,000 cells per well were seeded for the experiment. The test medium contained different concentrations of PACAP $\left(10^{-7} \mathrm{M}\right.$ to $10^{-11}$ $\mathrm{M})$ dissolved in Ringer's solution. Histamine concentrations were determined as described previously using a commercially available kit (AMAC, Westbrook, Massachusetts, USA). Data are presented as percent change in concentration over basal (control) concentration.

Somatostatin release. To determine the effect of PACAP and VIP on release of somatostatin from the D cell, a selectively enriched gastric D-cell preparation (15-30\% D cells) was produced by elutriation and density centrifugation from rat gastric mucosa as reported previously (4). Somatostatin was determined by radioimmunoassay. The medium, to which $50 \mathrm{~mL}$ Trasylol was added, was collected after 2 hours of incubation with or without peptides. Radioimmunoassay was performed with anti-somatostatin antibody (AB-8401) that had

$\mathbf{a}$

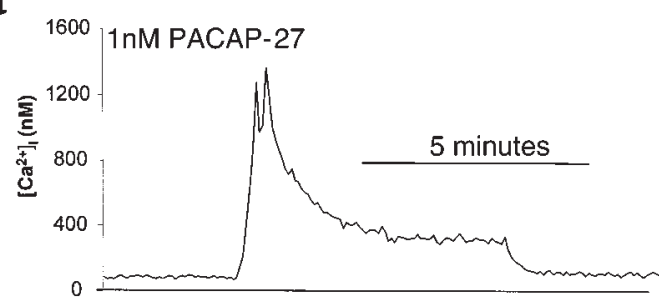

b

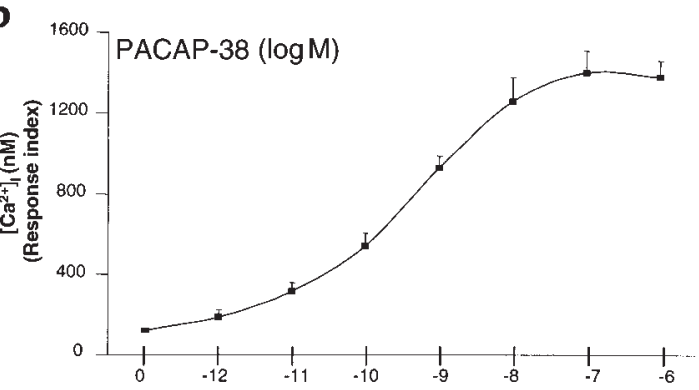

Figure 2

PACAP-induced stimulation of $\mathrm{Ca}_{2}{ }^{+}$in ECL cells. (a) PACAP-induced intracellular signaling in isolated $E C L$ cells: video imaging using Fura2/AM-loaded ECL cells as detailed in text. PACAP-27 was administered at a dose of $1 \mathrm{nM}$; the induction of a typical biphasic $\mathrm{Ca}^{2+}$ release is shown. (b) Dose response to PACAP of the averaged $\left[\mathrm{Ca}^{2+}\right]_{i}$ stimulation in response to various concentrations of PACAP-38. Data are presented as the $\mathrm{Ca}^{2+}$ response index, calculated as: (peak $\left[\mathrm{Ca}^{2+}\right]_{i}$ of responding cells $\times$ the percentage of cells responding)/100. sensitivity sufficient to detect somatostatin at 2.5 $\mathrm{pmol} / \mathrm{L}$. Measurement of $\mathrm{Ca}^{2+}{ }_{\mathrm{i}}$ was performed during superfusion, as described above.

In vivo measurements of gastric acid secretion. SpragueDawley rats (Harlan Sprague Dawley Inc., Indianapolis, Indiana, USA), weighing approximately 300 grams each and maintained on a regular Purina rat chow diet, were anesthetized with Inactin placed on a heated table to maintain rectal temperature at $37^{\circ} \mathrm{C}$, and tracheotomized according to the established animal use protocols of the Veterans Administration (VA) Greater Los Angeles Heath Care System at West Los Angeles. Catheters were placed into the femoral veins and laparotomy was performed to allow gastric cannula placement. Study duration was approximately 240 minutes. Lost fluids were replaced with normal isotonic saline $(0.9 \%$ $\mathrm{NaCl}$ ). After the establishment of stable basal gastric acid secretion, rats received either an infusion of anti-somatostatin antibody or sham treatment (vehicle alone). The indicated secretagogues $(10 \mathrm{nmol} / \mathrm{kg}$ per hour) were then administered using a peristaltic pump at $0.8 \mathrm{~mL}$ per hour for 2 hours after the start of the experiment. Gastric acid output was measured by titration using $10 \mathrm{mM}$ $\mathrm{NaOH}$ as the titrant.

Statistical analysis. Results are shown as mean \pm SEM. Statistical analysis of the data was performed by Mann-Whitney $U$ test if the Kruskal-Wallis test indicated a significant difference between multiple groups. For multiple comparisons with the same control group, the number of comparisons according to Bonferroni defined the limit of significance. Differences between paired groups were determined using paired Student's $t$ tests. Values were considered statistically significant when $P<0.05$.

\section{Results}

Identification of the PACAP receptor and its splice variants on ECL cells. To demonstrate that rat gastric ECL cells express splice variants of PAC1, RT-PCR has been performed previously using total RNA extracted from these purified, isolated ECL cells. Our amplified sequences corresponded to the PAC1 sequence described previously (10). Amplification of reverse transcribed RNA from ECL cells using primers specific for either VPAC1 or VPAC2 were negative (data not shown). To determine the specific splice variant(s) expressed by ECL cells, primers were used corresponding to the exon sequences of the rat "Hip," "HOP," "HipHOP," and null splice variants as described previously $(13,14)$. Amplification of transcription products was observed for all 4 of the major splice variants (Figure 1a). RT-PCR results from both procedures established the presence of PAC1 on the ECL cells. The sensitivity of RT-PCR does not exclude the possibility that other cell types contaminating the preparation (10-15\%) may also express PAC1, but clearly ECL cells do express PAC1 and do not express VPAC, given the functional responses described below.

A comparison of PAC1 expression in purified ECL and parietal cells is shown in Figure 1b. PAC1 is found only in ECL cells, whereas histidine decarboxylase is found mainly in ECL cells; H,K-ATPase is present in parietal cells but not in ECL cells. The absence of PAC1 in parietal cells is consistent with the confocal data presented below. 


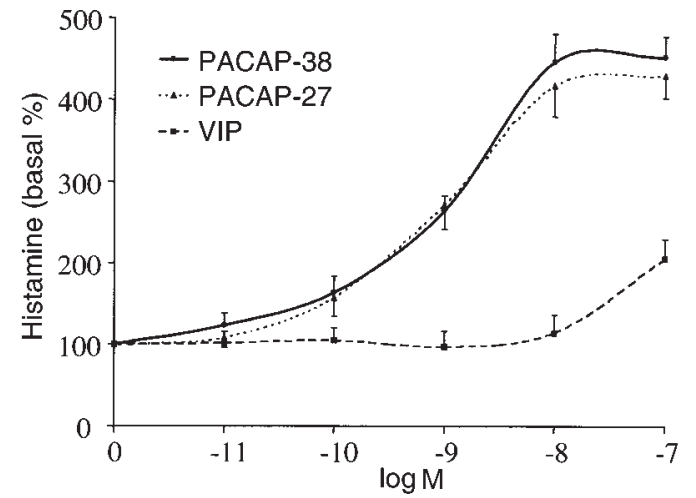

Figure 3

PACAP-induced stimulation of histamine release in isolated ECL cells. Doseresponse curves of histamine release from purified ECL cells to the indicated concentrations of PACAP-38 (circles), PACAP-27 (triangles), and VIP (squares). Data are expressed as percentage above basal histamine release and reflect the average of 4 experiments. Error bars reflect SEM; $n=4$.

Elevation of $\left[\mathrm{Ca}^{2+}\right]_{i}$ in ECL cells by PACAP. PAC1 is coupled to both cAMP and calcium signaling responses. ECL cells are too small for microinjection to allow measurement of cAMP changes in individual cells using the fluorescent subunits of $\mathrm{R}_{2} \mathrm{C}_{2}$. Although PACAP shows a dose-dependent elevation of cAMP of close to 10 -fold at $10^{8} \mathrm{M}$, pooled cells must be used for these measurements, and cross-talk from the $10 \%$ contaminating cells cannot be excluded (data not shown). Therefore, to determine the direct PACAP responsiveness of the members of the ( $90 \%$ pure) ECL cell population, $\left[\mathrm{Ca}^{2+}\right]_{i}$ was measured by video imaging of superfused preparations of isolated ECL cells using Fura-2 and microfluorimetry as described previously (4). With this approach, superfusion at a rate enabling 5 changes of chamber medium per minute eliminates cellular cross-talk.

The basal concentration of $\mathrm{Ca}^{2+}{ }_{\mathrm{i}}$ in the cultured cells was about $100 \mathrm{nM}$. PACAP-27 at a dose of $1 \mathrm{nM}$ (shown in the typical trace in Figure 2a) produced a biphasic $\left[\mathrm{Ca}^{2+}\right]_{i}$ increase in the ECL cells. The peak level was approximately $1.3 \mu \mathrm{M}$; steady-state $\left[\mathrm{Ca}^{2+}\right]_{\mathrm{i}}$ was elevated 2 -3-fold above basal levels. When PACAP-38 was removed from the superfusion medium, $\left[\mathrm{Ca}^{2+}\right]_{\mathrm{i}}$ returned to basal levels.

The response to PACAP-38 stimulation of the calcium signal was dose-dependent, with $8 \%, 46 \%, 85 \%$, and $96 \%$ of ECL cells responding to PACAP-38 at concentrations of $10^{-11} \mathrm{M}, 10^{-10} \mathrm{M}, 10^{-9} \mathrm{M}$, and $10^{-8} \mathrm{M}$, respectively. Thus all cells have splice variants of PAC1, but these may vary in number or coupling efficiency, perhaps accounting for the differences in the number of cells responding as a function of dose. The peak $\mathrm{Ca}^{2+}$ response in individual cells to PACAP-38 at $10^{-9} \mathrm{M}$ ranged from $360 \mathrm{nM}$ to $1,665 \mathrm{nM}$. To define a $\left[\mathrm{Ca}^{2+}\right]_{\mathrm{i}}$ dose response to PACAP-38 in this cultured ECL cell population, the $\mathrm{Ca}^{2+}$ response was averaged over the cell population, and was expressed as a response index: (peak $\left[\mathrm{Ca}^{2+}\right]_{\mathrm{i}}$ of responding cells $\times$ percentage of responding cells)/100; this was calculated at each level of PACAP. The $\mathrm{EC}_{50}$ for this averaged signal was approximately $10^{-9} \mathrm{M}$ (Figure $2 \mathrm{~b}$ ). PACAP-27 was equally effective in stimulating $\mathrm{Ca}^{2+}$ signaling, but VIP was relatively ineffective as a stimulant of calcium signaling in this cell preparation (data not shown).
Stimulation of ECL histamine release by PACAP. To determine the functional effect of PACAP on isolated gastric ECL cells, the release of histamine from ECL cells was examined after exposure to PACAP. Stimulation by both PACAP-38 and PACAP-27 increased histamine release to a maximum of 4-fold over basal values. PACAP-38 and PACAP-27 dose-dependently increased histamine release with similar efficiency in the isolated ECL cells (Figure 3). Detectable stimulation was observed at $0.1 \mathrm{nM}$, maximal stimulation at approximately $10 \mathrm{nM}$, and half maximal stimulation at about $0.5 \mathrm{nM}$ for both PACAP-27 and PACAP-38. This correlates with the dose response observed for the stimulation of calcium signals. Stimulation of ECL cell histamine release by VIP was about 1,000-fold less potent in stimulating histamine release from ECL cells than was PACAP, for which increased release was first observed at $100 \mathrm{nM}$. This indicates that the effect of PACAP on ECL cells was due to PAC1and not to VPAC1 or VPAC2.

Effect of PACAP-38 in intact gastric glands. To explore the action of PACAP in a more integrated system, PACAP-38 was superfused across rabbit gastric glands loaded with Fluo-4/AM. (This dye had to be used instead of Fura-2 because the UV laser lines are not appropriate for Fura 2.) ECL cells load with Fluo-4 dyes to a greater extent than do parietal cells, presumably due to accumulation of the dye in secretory vacuoles. ECL cells in the rabbit gastric glands used in this study can be identified by this loading characteristic, their size, number, location, and the accumulation of acridine orange in their secretory vacuoles. In the confocal microscope experiments, only single sections are shown, displaying only a single ECL cell but several parietal cells, reflecting the relative numbers of these 2 cell types. There was an increase of $\left[\mathrm{Ca}^{2+}\right]_{i}$ in the ECL cells (defined either by their high fluorescence or subsequent accumulation of acridine orange in their vacuoles) caused by the addition of PACAP. This is shown in the selected confocal images from the experiment and in the scan of a defined region of the images throughout the whole experiment in Figure 4a. This increase in $\left[\mathrm{Ca}^{2+}\right]_{\mathrm{i}}$ in the ECL cells was followed by a calcium transient in parietal cells as shown in the scan. It can be seen that other parietal cells also increased their $\left[\mathrm{Ca}^{2+}\right]$. The data presented are typical of several experiments in which both cell types were stimulated, but the parietal cell signal always followed the ECL cell signal with a significant delay ( 100 seconds).

The transient in the parietal cells (but not in the ECL cells) was blocked by the histamine-2 receptor antagonist ranitidine (Figure 4b). Histamine itself produced a transient signal in parietal cells but not in ECL cells (Figure $4 \mathrm{c}$ ), as has been shown previously (22). Thus PACAP in this model first stimulates ECL cell calcium signaling, and then, by histamine release and activation of the histamine2 receptor, parietal cell calcium signals. The presence of histamine-2 receptor antagonists abolished the effect of PACAP on parietal cells but not ECL cells, demonstrating that there is not an independent PAC1 on parietal cells. Isolated parietal cells respond to carbachol but not to PACAP (data not shown).

Stimulation of D cells by VIP and PACAP. The previously described in vivo data $(18,19)$ showing inhibition of gastrin-stimulated acid secretion could be a result of D-cell 

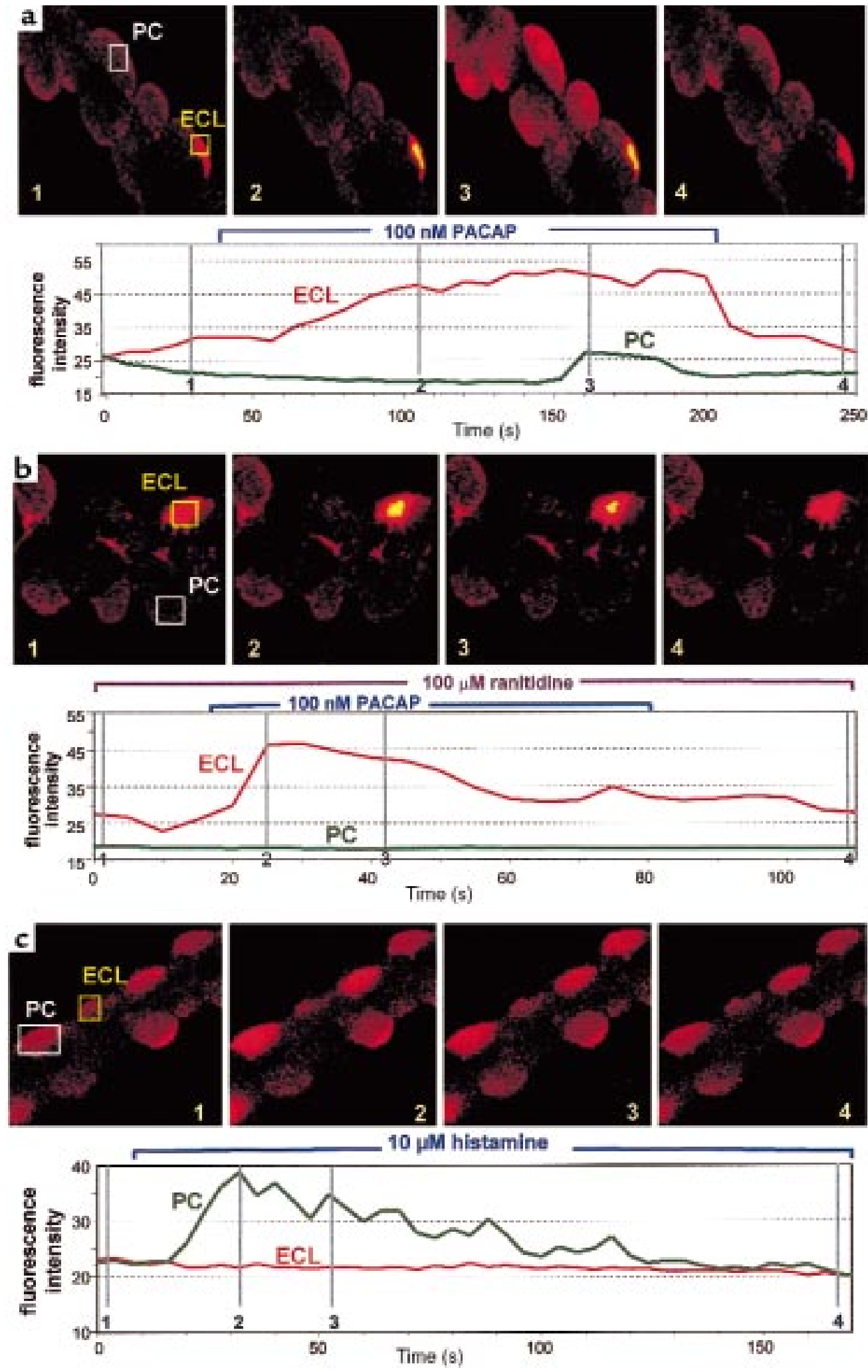

Figure 4

Effect of PACAP and histamine on superfused Fluo-4-loaded gastric glands using confocal microscopy. (a) In the first sequence, PACAP-38 (100 nM) was added to the perfusate; it can be seen that first the ECL cell $\left[\mathrm{Ca}^{2+}\right]_{\mathrm{i}}$ and then the parietal cell $\left[\mathrm{Ca}^{2+}\right]_{i}$ is elevated. The position of the images on the trace for $\left[\mathrm{Ca}^{2+}\right]_{i}$ is presented on the image and in the vertical lines in the lower trace, which shows the calcium level throughout the experiment. The rectangular images represent the regions of the total image that were chosen to generate the scan of the calcium signal. (b) $100 \mu \mathrm{M}$ ranitidine was added to the perfusate before PACAP addition; although the ECL cell response is retained, the parietal cell response is abolished, as shown in the images and in the trace for $\left[\mathrm{Ca}^{2+}\right]_{i}$. (c) Effect of $10 \mu \mathrm{M}$ histamine on parietal cells $\left[\mathrm{Ca}^{2+}\right]_{\text {. }}$. The lower panel shows the calcium signal in a parietal cell. No changes were observed in ECL cells with this ligand. Images are representative of at least 4 separate experiments, carried out on different preparations. 
stimulation by injected PACAP. To determine the effect of PACAP and VIP on D cells, gastric D cells were isolated, and calcium signals and somatostatin release were measured in response to PACAP-27 and VIP. As shown in Figure 5a, which compares the responses of D cells and ECL cells, VIP administration resulted in a biphasic signal of $\mathrm{Ca}^{2+}{ }_{i}$ only in D cells, whereas PACAP produced a signal in both cell types; in $\mathrm{D}$ cells, the peak response to PACAP was slightly larger than that caused by VIP. Both VIP and PACAP stimulated somatostatin release in a dose-dependent fashion. PACAP-27 and PACAP-38 both had detectable stimulation at $0.01 \mathrm{nM}$, half-maximal stimulation at $0.1 \mathrm{nM}$, and maximal stimulation at $1 \mathrm{nM}$. The effects of VIP were similar to those of both PACAP-27 and PACAP-38 in stimulating somatostatin release, with detectable stimulation at $0.01 \mathrm{nM}$, halfmaximal stimulation at $0.1 \mathrm{nM}$, and maximal stimulation at between $1 \mathrm{nM}$ and $10 \mathrm{nM}$ (Figure $5 \mathrm{~b}$ ). With both ligands, the response tended to decrease at the highest concentration tested $(100 \mathrm{nM})$. Thus, in contrast to the ECL cell response, PACAP and VIP have similar efficacy in stimulating D cells, suggesting that on D cells, VPAC rather than PAC1 are the dominant receptors responsible for release of the paracrine inhibitor somatostatin.

Gastric acid stimulation by PACAP in rats. Previous work had shown either no effect or inhibition of acid secretion by intravenous administration of PACAP $(18,19)$. Given the effect of this peptide on ECL cell function as shown above, it seemed possible that the stimulatory effect of PACAP was masked by stimulation of fundic $D$ cells by the injected hormone, perhaps at a VIP receptor as suggested by the results from our tests on D cells. Hence, anti-somatostatin antibody was used to try to reveal the stimulation of secretion in the intact animal that is expected based on the in vitro effects observed using ECL cells. In rats treated with a nonspecific antibody, administration of PACAP-38 resulted in an increase of $50 \%$, from a baseline of $5 \mu \mathrm{Eq} / 10 \mathrm{~min}$ to a maximum of $7.5 \mu \mathrm{Eq} / 10 \mathrm{~min}$. After infusion with PACAP-38 and neutralizing anti-somatostatin antibody, acid output increased nearly 3 -fold, from a basal value of $5 \mu \mathrm{Eq} / \mathrm{h}$ to a maximal output of nearly $15 \mu \mathrm{Eq} / \mathrm{h}$ (Figure 6a).

A similar acid secretory response was observed in different groups of animals after the administration of either PACAP-27 or PACAP-38. Hourly acid output is displayed in Figure 6b, which shows that these 2 peptides have similar effects on acid secretion. The measured rate of acid secretion was similar to that found with administration of pentagastrin in our laboratory.

\section{Discussion}

Peripheral mediation of the cephalic phase of gastric acid secretion was long considered to occur within the gastric epithelium as a result of the release of acetylcholine from gastric neurons (1). This belief was based largely on the observation that muscarinic antagonists such as atropine or pirenzepine $(1,7)$ inhibited vagal stimulation of acid secretion. Isolated rabbit gastric glands and parietal cells respond to carbachol with a transient increase of acid secretion that is due to activation of an $\mathrm{M}_{3}$ receptor subtype, showing that there is a direct action of acetylcholine on the parietal cell (7).

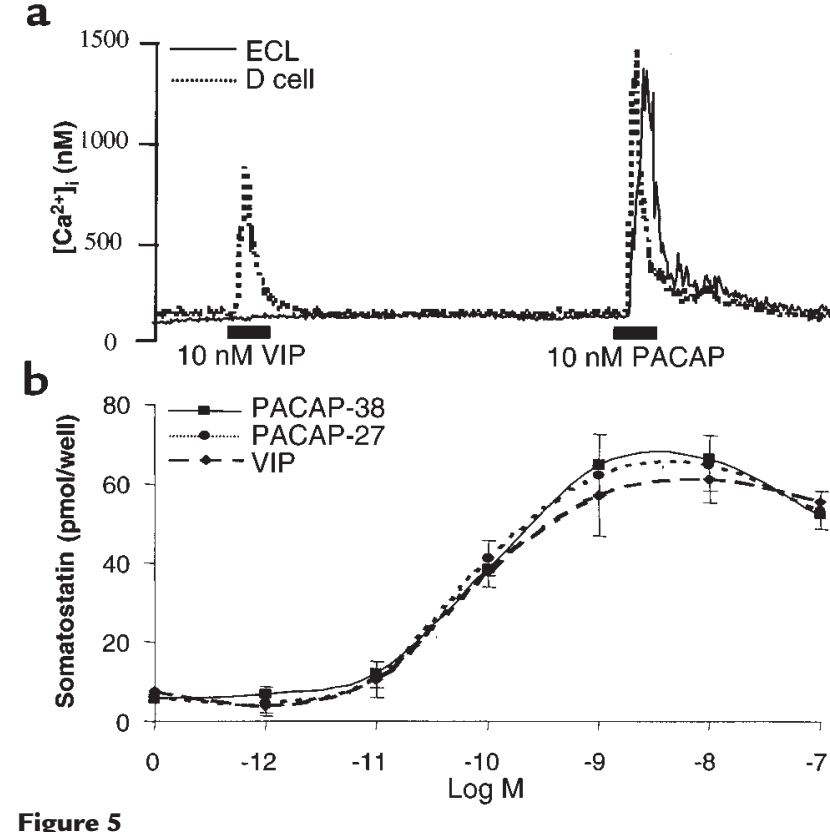

Figure 5

Effects of VIP and PACAP on D cells. (a) Comparison of the effects of VIP and PACAP on $\left[\mathrm{Ca}^{2+}\right]_{\mathrm{i}}$ in isolated D cells and ECL cells in the same preparation. For these experiments, Fura- 2 was used as the $\mathrm{Ca}_{2}{ }^{+}$i probe; data represent at least 3 experiments on those preparations. (b) Stimulation of somatostatin secretion in isolated rat gastric $D$ cells by the indicated concentrations of PACAP-38 (circles), PACAP-27 (triangles), and VIP (squares). Data are representative of the mean of 4 experiments; error bars reflect SEM; $n=4$.

After the development of histamine- 2 receptor antagonists, it was observed that about $60 \%$ of vagally induced secretion was sensitive to these antagonists (6). This finding suggested that histamine release from ECL cells caused by acetylcholine was responsible for at least half of vagally stimulated acid secretion.

When ECL cells were isolated and purified to the point that their functional responses could be measured, it was found that a cellular response to carbachol in terms of calcium signaling and histamine release could not be demonstrated $(3,4)$. Therefore, the mediator of vagal stimulation of acid secretion induced by activation of the ECL cell is unlikely to be acetylcholine. All ECL cells responded to gastrin through a CCK-B receptor subtype, showing the integrity of this receptor; $G$ cells similarly prepared responded fully to a variety of ligands, including carbachol, showing that the muscarinic receptor is also not destroyed by digestion. Furthermore, carbachol stimulated calcium signals in parietal cells in superfused rabbit gastric glands, with little observed change in ECL cells (data not shown), again demonstrating that muscarinic receptors survived the preparation procedure.

Various neural peptides are present in the enteric nervous system, such as galanin and PACAP, that may mediate the cephalic phase of acid secretion. Galanin has been shown to inhibit ECL cell function, both in terms of gastrin-induced calcium signaling and histamine release, making this peptide a candidate as a neural mediator of central inhibition of acid secretion $(5,23,24)$. RT-PCR indicated that perhaps both galanin-1 and galanin-2 receptors might be implicated in this ECL cell response. 


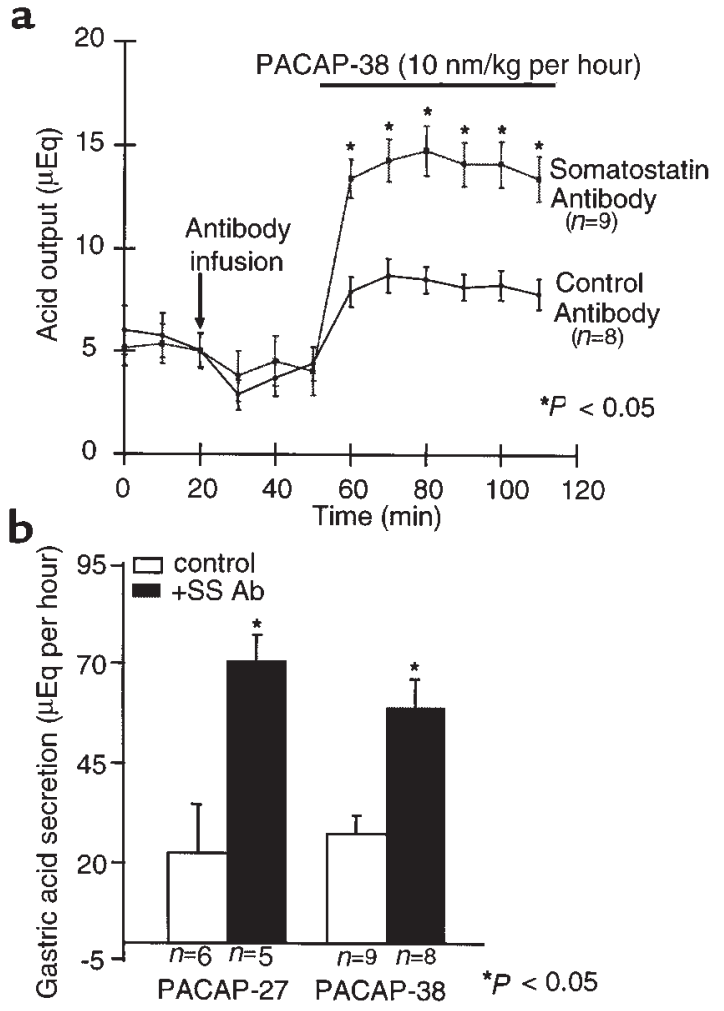

Figure 6

PACAP- and VIP-induced stimulation of gastric acid secretion in rats. (a) Level of gastric acid secretion in 2 groups of fistula rats after the administration of PACAP with or without the anti-somatostatin antibody. After a resting period of 1.5-3 hours (to establish baseline), 1 group of rats $(n=5)$ received somatostatin antibody (squares) and another group $(n=6)$ received control antibody at $20 \mathrm{~min}$. All rats received PACAP-38 (10 nmol/kg per hour); gastric acid was assessed by titration. Differences between paired groups were determined using paired Student's $t$ tests. ${ }^{*} P<0.05$. (b) Total hourly gastric acid secretion $(\mu \mathrm{Eq} / \mathrm{h})$ in fistula rats after the administration of PACAP-27 (left) or PACAP-38 (right), with or without the administration of the anti-somatostatin antibody. Antibody alone had no effect on acid secretion. All rats received the indicated peptide $(10 \mathrm{nmol} / \mathrm{kg}$ per hour); gastric acid was assessed by titration. Differences between paired groups were determined using paired Student's $t$ tests. ${ }^{*} P<0.05$.

Peptide YY was also an effective inhibitor of ECL cell function. Acting at a Y1 receptor, peptide YY is therefore perhaps involved in the intestinal phase of regulation of ECL cell function (25). Thus, there is reasonable evidence for neural mediators of inhibition of ECL cell function.

PACAP is found in the enteric nervous system and in gastric nerve fibers (9). It is therefore possible that neural stimulation may release this neuropeptide in the vicinity of ECL cells. The experimental data presented above show that PACAP is a functional ligand on the rat ECL cell surface. Western analysis has shown the presence of PAC1 in ECL cell membranes (26), and there is, in this cell type, expression of all the splice variants of PAC1, as demonstrated by RT-PCR. No VPAC1 or VPAC2 was detected with any of the primers, which were selected to span intron-exon junctions (primers that prevent spurious signals from genomic DNA). PAC1 is functionally coupled to calcium signaling in the ECL cell and to histamine release. It has also been shown that PACAP stimulates ECL cell multiplication in vitro (20). This might indicate that PACAP is a trophic factor for ECL cells in addition to the well-described effect of gastrin; release of this neuropeptide might provide a tonic stimulant for maintenance of ECL cells in the absence of gastrin stimulation.

Furthermore, the release of histamine induced by PACAP activates calcium signaling in the parietal cell, as measured in the intact gland preparation. Histamine-2 receptor antagonism fully inhibited the parietal cell response without affecting the ECL cell response. These gland-based data establish that PACAP stimulates histamine release in a model of gastric function that is more integrated than a model using isolated cells, and also show the absence of a PAC1 subtype on the parietal cell, as did RT-PCR and calcium signaling studies on isolated parietal cells (data not shown). It is tempting to speculate that PACAP release from gastric nerves is in part responsible for the histaminergic component of gastric acid secretion.

However, administration of PACAP had been shown to inhibit gastrin-stimulated acid secretion $(18,19)$. PACAP and VIP are equipotent at VPAC, although PACAP-27 or PACAP-38 are about 1,000 fold more potent at PAC1 (10, 14). If somatostatin was released from $D$ cells due to PACAP injection, the potent action of somatostatin as an inhibitor of ECL cell function acting at a type 2 somatostatin receptor subtype $\left(\mathrm{IC}_{50} 10^{-10} \mathrm{M}\right)$ could dominate the resultant response of the stomach to PACAP injection (5, 27). In accordance with this hypothesis, it is shown here that, when a neutralizing somatostatin antibody is present during PACAP administration, PACAP becomes a potent stimulant of acid secretion. A direct action on the D cell by PACAP is shown by the observation of PACAPinduced calcium signaling and somatostatin release by isolated D cells. The action of VIP on somatostatin release from $D$ cells is similar to that of PACAP, indicating the presence of VPAC rather than PAC1 on the D cell.

Injection of PACAP probably stimulates the VIP receptor VPAC on the D cell, as well as PAC1 on the ECL cell, with the former dominating the effect on acid secretion. Physiologically, with cephalic stimulation of both acetylcholine and PACAP release from postganglionic fibers, acetylcholine is expected to functionally inhibit D cells, and thus may allow PACAP effects on ECL cell histamine release to be coupled to stimulation of parietal cell secretion. This would not be the case with PACAP injection, because acetylcholine would not be involved, and PACAP would stimulate VPAC on D cells. Alternatively, PACAP nerves may terminate only in the vicinity of ECL cells, which are in a different location from fundic D cells.

Based on these data, from both in vitro and in vivo experiments, it appears likely that PACAP, released from postganglionic nerves in the vicinity of fundic ECL cells, can mediate the component of central vagal stimulation that depends on activation of the histamine- 2 receptor on the parietal cell, reflecting histamine- 2 antagonism of cephalic stimulation. The PAC1 splice variants selectively expressed on ECL cells - and not on parietal cells, as demonstrated by RT-PCR and previously by Western blot analysis (26) - are functionally coupled to increases of $\left[\mathrm{Ca}^{2+}\right]_{i}$ and the release of histamine. Intact gastric gland experiments show that ECL stimulation by 
PACAP is coupled to parietal cell responses through histamine release and stimulation of the histamine-2 receptor present on the latter. ECL cell. These pharmacological data implicate PACAP as a neuropeptide that is possibly involved in regulation of gastric acid secretion, as evidenced by its effect in vivo in the presence of neutralizing somatostatin antibody. It seems that whereas gastrin and somatostatin are positive and negative endocrine/paracrine regulators of ECL cell function, PACAP and galanin are candidate peptides for positive and negative neural mediation of the regulation of acid secretion, respectively.

\section{Acknowledgments}

We thank Yvette Tache for stimulating ideas and discussion. This work was supported by US VA Senior Medical Investigator Award funds; National Institutes of Health grants DK-40615, DK-41301, DK-17294, and DK-5227401; AGA IRSA; and a VA Career Development Award.

1.Hersey, S.J., and Sachs, G. 1995. Gastric acid secretion. Physiol. Rev. 75:155-218.

2. Walsh, J.H. 1994. Gastrointestinal hormones. In Physiology of the gastrointestinal tract. L.R. Johnson, editor. Raven Press. New York, NY. 1-129.

3. Prinz, C., et al. 1993. Histamine secretion from rat enterochromaffinlike cells. Gastroenterology. 105:449-461.

4.Zeng, N., et al. 1996. Selective ligand-induced intracellular calcium changes in a population of isolated gastric endocrine cells. Gastroenterology. 110:1835-1846.

5. Lindstrom, E., et al. 1997. Neurohormonal regulation of histamine and pancreastatin secretion from isolated rat stomach ECL cells. Regul. Pept. 71:73-86.

6. Yanagisawa, K., Yang, H., Walsh, J.H., and Tache, Y. 1990. Role of acetylcholine, histamine and gastrin in the acid response to intracisternal injection of TRH analog, RX 77368, in the rat. Regul. Pept. 27:161-170.

7. Wilkes, J.M., Kajimura, M., Scott, D.R., Hersey, S.J., and Sachs, G. 1991. Muscarinic receptors of gastric parietal cells. J. Membr. Biol. 122:97-110.

8. Miyata, A., et al. 1989. Isolation of a novel 38 residue-hypothalamic polypeptide which stimulates adenylate cyclase in pituitary cells. Biochem. Biophys. Res. Commun. 64:567-574.

9. Sundler, F., et al. 1992. Pituitary adenylate cyclase-activating polypeptide: a novel vasoactive intestinal peptide-like neuropeptide in the gut. Neuroscience. 46:439-454.

10. Pisegna, J.R., and Wank, S.A. 1993. Molecular cloning and functional expression of the pituitary adenylate cyclase-activating polypeptide type
I receptor. Proc. Natl. Acad. Sci. USA. 90:6345-6349.

11. Ishihara, T., Shigemoto, R., Mori, K., Takahashi, K., and Nagata, S. 1992. Functional expression and tissue distribution of a novel receptor for vasoactive intestinal polypeptide. Neuron. 8:811-819.

12. Harmar, A.J., et al. 1998. International Union of Pharmacology. XVIII. Nomenclature of receptors for vasoactive intestinal peptide and pituitary adenylate cyclase-activating peptide. Pharmacol. Rev. 50:265-270.

13. Spengler, D., et al. 1993. Differential signal transduction by five splice variants of the PACAP receptor. Nature. 365:170-175.

14. Pisegna, J.R., and Wank, S.A. 1996. Cloning and characterization of the signal transduction of four splice variants of the human pituitary adenylate cyclase activating polypeptide receptor. Evidence for dual coupling to adenylate cyclase and phospholipase C. J. Biol. Chem. 271:17267-17274.

15. Deutsch, P.J., and Sun, Y. 1992. The 38-amino acid form of pituitary adenylate cyclase-activating polypeptide stimulates dual signaling cascades in PC12 cells and promotes neurite outgrowth. J. Biol. Chem. 267:5108-5113.

16. Mizuta, K., Ozawa, M., Aono, M.M., and Moriga, M. 1994. Centrally administered PACAP stimulated gastric acid secretion in anesthetized rats. Biomed. Res. 15(Suppl. 2):253-256.

17. Zeng, N., Bayle, D.B., Walsh, J.H., Kang, T., and Sachs, G. 1996. Localization of PACAP receptor on rat fundic ECL cells and D cells. Gastroenterology. 110:A1131.

18. Mungan, Z., Ozmen, V., Ertan, A., and Arimura, A. 1992. Pituitary adenylate cyclase-activating polypeptide-27 (PACAP-27) inhibits pentagastrinstimulated gastric acid secretion in conscious rats. Regul. Pept. 38:199-206.

19. Mungan, Z., Ozmen, V., Ertan, A., and Arimura, A. 1995. Effect of PACAP on gastric acid secretion in rats. Peptides. 16:1051-1056.

20. Lauffer, J.M., et al. 1998. Pituitary adenylate cyclase-activating polypeptide (PACAP) modulates gastric enterochromaffin-like (ECL) cell proliferation in rats. Gastroenterology. 114:A1158.

21. Chew, C.S., Hersey, S.J., Sachs, G., and Berglindh, T. 1980. Histamine responsiveness of isolated gastric glands. Am. J. Physiol. 238:G312-G320.

22. Chew, C., 1986. Cholecystokinin, carbachol, gastrin, histamine, and forskolin increase $\left[\mathrm{Ca}^{2+}\right]_{\mathrm{i}}$ in gastric glands. Am. J. Physiol. 250:G814-G823.

23. Zeng, N., Kang T., Wen Y., Walsh, J.H., and Sachs, G. 1998. Galanin inhibition of ECL cell function. Gastroenterology. 115:330-339.

24. Rossowski, W.J., and Coy, D.H. 1989. Inhibitory action of galanin on gastric acid secretion in pentobarbital-anesthetized rats. Life Sci. 45:1807-1813.

25. Zeng, N., Walsh, J.H., Kang, T., Wu, S.V., and Sachs, G. 1997. PYY inhibition of rat gastric ECL cell function. Gastroenterology. 112:127-135.

26 . Zeng, N., et al. 1998. The pituitary adenylate cyclase activating polypeptide type 1 receptor (PAC1-R) is expressed on gastric ECL cells: evidence by immunocytochemistry and RT-PCR. Ann. NY Acad. Sci. 865:147-156.

27. Prinz, C., Sachs, G., Walsh, J.H., Coy, D.H., and Wu, S.V. 1994. The somatostatin receptor subtype on rat enterochromaffin-like cells. Gastroenterology. 107:1067-1074. 